\title{
Antenatal depression and anxiety in primiparous Polish mothers and fathers
}

\author{
Eliza Kiepura®i), Grazyna Kmita®
}

The Institute of Mother and Child, Warsaw, Poland

\begin{abstract}
Objectives: Mood disturbances are the most prevalent mental health problems in expectant parents. The knowledge about the factors which increase the risk of perinatal depression is insufficient, especially in fathers. The aims of the present study were to estimate the prevalence and to compare mean levels of antenatal depression and anxiety as well as to examine the relationship between the risk for depression and anxiety in primiparous Polish parents.

Material and methods: 250 parental couples participating in antenatal classes took part in the study. Depression and anxiety were measured with the Edinburgh Postnatal Depression Scale (EPDS) and the State-Trait Anxiety Inventory (STAI), respectively. Paired t-test with bootstrapping was applied to compare parental EPDS, as well as STAI raw scores. Pearson correlation coefficients were calculated for depression and anxiety scores for women and men separately. The factors predictive for the increased risk of depression were investigated with the use of a multivariate logistic regression analysis.

Results: $10 \%$ of women and $4 \%$ of men were at risk of depression. High level of state anxiety was found in $7.7 \%$ of expectant mothers and $10 \%$ of fathers, whereas elevated state anxiety was found in $19 \%$ of both parents. EPDS scores correlated moderately with anxiety. The risk of depression was increased by state anxiety in the case of mothers and by trait anxiety in the case of fathers.

Conclusions: High level of anxiety increases the risk of antenatal depression. Both parents should be screened for depression and anxiety in the prenatal period.
\end{abstract}

Key words: antenatal depression; antenatal anxiety

Ginekologia Polska 2020; 91, 1:24-28

\section{INTRODUCTION}

While becoming a competent and sensitive caregiver involves a series of changes in many aspects of the new parents'lives, pregnancy is an adaptive time of psychological transformation and adjustment [1]. Transition to parenthood, however, is also a challenging period of disequilibrium and increased psychological distress [2, 3]. A vast body of research confirms the perinatal period as associated with heightened vulnerability to mental health concerns [4-8]. Depression and anxiety are widely recognized as the most prevalent mood disturbances in expectant and new mothers and fathers $[5,9,10]$. According to available data, perinatal depression affects approximately $10-23.8 \%$ of women and $2-10 \%$ of men, whereas up to $28 \%$ of mothers and $14 \%$ of fathers suffer from anxiety [9-13]. It is also known that maternal and paternal depression is significantly correlated. The increase in one parent's symptomatology corresponds with the worsening of the other partner's mental health $[12,14]$.
Despite a growing number of research in the field of perinatal psychopathology, prevalence and trajectories of antenatal depression and anxiety were investigated to a lesser extent as compared to parental postnatal mood disorders [13]. It was proved, however, that prenatal mental health difficulties are a predictor and a risk mechanism for the postnatal psychopathology [15-17]. This is of special clinical and public health importance, as impaired parental mental well-being during pregnancy is significantly associated with perinatal as well as long-term adversity. Numerous studies evidenced that maternal perinatal mood disorders may lead to such detrimental consequences as obstetric complications, postpartum mental health disorders, disturbances in mother-infant interactions and caregiving, alternations in child development and child developmental outcomes [9, 18-20].

The analogous knowledge about men is relatively less extended and partially inconsistent [14, 21]. Existing literature on antenatal emotional well-being in men documents 
that, similarly to maternal psychopathology, paternal perinatal depression is significantly associated with impaired fathers' parenting and father-child interactions, long-term psychological problems in children and emotional well-being of spouses [21-23]. However, the paternal vulnerability to depression and anxiety as well as the prevalence and course of mental health problems in perinatal period in men remain unclear. For instance, Teixeira and colleagues [9] found higher rates of depression and anxiety in mothers. Their study results also revealed different patterns of mood disturbances throughout pregnancy: decrease in depression and increase in anxiety in both mothers and fathers. Increase in anxiety was not confirmed by Leach and the team [5]. According to systematic review carried out by the researchers, paternal anxiety was common in perinatal period and remained stable across the pregnancy. Korja et al. [13], on the other hand, reported low levels of depression and anxiety symptoms during the whole pregnancy in both mothers and fathers as well as similar and not gender-specific trajectories of perinatal mood disturbances.

Regardless of gender differences, parental antenatal depression is a well-documented risk factor for postnatal depression. Multiple studies showed the continuity of mood disorders throughout the perinatal period in both mothers and fathers [15]. A large number of studies also confirmed the link between parental perinatal mood disorders and developmental abnormalities in children [24]. In some longitudinal studies antenatal maternal depression was found to be associated with child's difficult temperament in infancy [18, 25], emotional and behavioral problems in childhood [26], and mental health problems in adolescence [27]. According to publications from the Avon Longitudinal Study of Parents and Children (ALSPAC) maternal prenatal depression was linked to developmental delays in toddlers at 18 months of age [28], whereas paternal antenatal depression was associated with behavioral problems in 42-month-old children as well as with psychiatric diagnosis in 7-year-olds [22]. Additionally, the risk of developmental problems was higher when fathers were depressed both pre- and postnatally. Still, further investigation is needed to widen the knowledge about the factors predicting prenatal depression in both mothers and fathers.

\section{Objectives of the current study}

Perinatal mental health in parents, and especially in fathers, needs further exploration [14]. There is scarce research on the prevalence of antenatal mood disorders in the group of Polish primiparous parents. Thus, the aims of the present study were 1) to estimate the prevalence of antenatal depression and anxiety (state and trait) in both expectant mothers and fathers, 2) to compare mean levels of depression, state anxiety and trait anxiety between the sexes, and 3) to examine the relationship between the risk for antenatal depression and anxiety in the group of primiparous mothers as well as fathers. Additionally, models of variables, which could explain an increased risk for antenatal depression in mothers and fathers, were sought for.

\section{MATERIAL AND METHODS}

The subjects

Two hundred and fifty pairs of expectant parents (mothers and fathers) were invited to take part in the study. The inclusion criteria comprised: $24^{\text {th }}-37^{\text {th }}$ week of gestation, primiparity, no major pregnancy complications, participation in typical forms of antenatal education. All parents gave written informed consent for their participation. The study was conform to the Declaration of Helsinki.

Eventually, 229 women and 181 men who met the required criteria were enrolled. The participants were recruited over a period of 12 months via antenatal classes, which were organized at four different obstetric units in a capital city with the population of around 2 million. The sample consisted of subjects with predominantly higher education (at least Bachelor's degree in $91 \%$ of women and $80 \%$ of men), within an age range of 21 to 40 years in the case of women $(M=29, S D=3.3$.), and 23 to 42 years in the case of men $(M=30, S D=3.55)$. The mean week of gestation was 30.47 (SD = 2.95), the median value was 31 weeks, whereas the minimum and the maximum values were, as assumed, 24 and 37 weeks, respectively. Around $40 \%$ of participants were examined during the spring/summer courses, whereas the remaining $60 \%$ during the autumn/winter courses.

\section{Procedure and measures}

Correlational study design was used. The subjects were asked to complete a set of questionnaires on a single occasion during the third trimester of pregnancy, after an antenatal class meeting. Depression and anxiety were measured with self-report questionnaires, the Edinburgh Postnatal Depression Scale (EPDS) [29] and the State-Trait Anxiety Inventory (STAI) [30], respectively. In addition, the subjects were also asked to complete a brief demographic survey with questions concerning their sex, age, education, socioeconomic status, obstetric factors (e.g. gestational age, previous history, etc.), their unborn baby's sex (if known), and the number of times the baby was seen on the ultrasound. The final task was writing a short description of the unborn child (up to 3-5 sentences). This was a qualitative part of the study and its results are not to be reported here.

\section{Data analytical approach}

Statistical analyses were conducted with IBM SPSS Statistics 24.0 (Predictive Solutions) and STATISTICA 13 (Statsoft). Descriptive statistics were used to describe the basic features of the data. Paired t-test with bootstrapping was 
used to compare maternal and paternal EPDS, as well as STAI raw scores. As depression can be a seasonal phenomenon, the effect of the measurement timing (autumn/winter vs spring/summer) was controlled for. In addition, Pearson correlation coefficients were calculated for EPDS and STAI scores for women and men separately. A multivariate logistic regression analysis was undertaken to investigate the factors predictive for the increased risk of depression. Generalized Linear/ Nonlinear Model analysis in STATISTICA 13 was used, and specifically Binomial Linear Model with Logit link function. Backward stepwise procedure was used with $5 \%$ criterion of significance for adding, and $10 \%$ for removing a variable.

\section{RESULTS}

Increased risk of depression (EPDS score of 12 points and more) was observed in almost $10 \%$ of 229 women and $4 \%$ of 181 men who took part in the study. Complete data from both of the partners were obtained for 169 pairs. Out of these, in the case of $85.8 \%$ of couples neither of the partners had an elevated risk of depression, in $1.2 \%$ of couples both partners had an elevated risk of depression, in $10 \%$ of couples only the woman had an elevated risk of depression, and in $3 \%$ of couples increased risk of depression was observed in the man only. Significant differences were found between the raw scores of women and men in EPDS, with medium effect size $(p<0.01$; Cohen's $d=0.497)$. No statistically significant results were found in EDPS scores of parents participating in summer versus winter courses (all ps $>0.05$ ).

\begin{tabular}{|c|c|c|c|c|c|c|}
\hline & \multicolumn{3}{|c|}{$\begin{array}{l}\text { Expectant mothers } \\
n=169\end{array}$} & \multicolumn{3}{|c|}{$\begin{array}{l}\text { Expectant fathers } \\
n=169\end{array}$} \\
\hline & Mean & SD & Range & Mean & SD & Range \\
\hline $\begin{array}{l}\text { Risk of } \\
\text { depression }\end{array}$ & 7.16 & 3.47 & 0-19 & 4.484 & 3.435 & 0-19 \\
\hline State anxiety & 34.73 & 8.502 & $19-66$ & 34.286 & 8.04 & $17-58$ \\
\hline Trait Anxiety & 37.78 & 7.259 & $23-62$ & 33.948 & 7.336 & $20-58$ \\
\hline
\end{tabular}

In the study, $4 \%$ of women and $4.7 \%$ of men had high scores of trait anxiety (at the level of 8-sten score or higher). High level of state anxiety was found in the case of $7.7 \%$ of women and almost $10 \%$ of men, whereas elevated state anxiety (7-sten score or higher) was found in as many as 19\% of both expectant mothers and fathers. Although no statistically significant differences were found in the mean scores of state anxiety between women and men ( $p>0.05)$, trait anxiety differentiated the two sexes, with higher raw scores in the case of women ( $p<0.01$; Cohen's $d=0.355$, small effect size). No effects were found for participants of autumn/winter vs spring/summer courses (all ps $>0.05$ ). Raw scores of EPDS and STAI in both parents are presented in Table 1, whereas the results of paired t-test with bootstrapping in Table 2 .

As could be expected, there was a positive moderate correlation between EPDS scores and the level of both state and trait anxiety (Pearson's $r$ for women: 0.525 and 0.54 , respectively; Pearson's $r$ for men: 0.555 and 0.632 , respectively).

In the next step, a model of variables that could best explain a higher risk of depression, separately for expectant mothers and fathers, was sought for. The risk of depression was treated as a dichotomized variable with two values:"Iow risk" (EDPS score less than 12 points) and "high risk" (EDPS score equal to or higher than 12 points). The initial set of variables comprised: trait anxiety (raw score), state anxiety (raw score), parental level of education (Bachelor's degree or higher vs secondary education or lower), time of antenatal course (autumn/winter vs spring/summer). For women, the only variable left in the model was state anxiety. The model's goodness of fit was sufficient (Hosmer-Lemeshow test $=7.437, p=0.385$; AUC: 0.8145 ). Each point more in the state anxiety scale increased the risk of depression in women 1.2 times. In addition, having state anxiety at the level of 8 stens and more increased the risk of depression in women 16 times $[\mathrm{OR}=16.24,95 \% \mathrm{Cl}=(4.89,53.88), \mathrm{p}<0.001]$.

As expectant fathers were concerned, the only variable left in the model was trait anxiety. Each point more in the trait anxiety scale seemed to increase the risk of depression in men 1.23 times. What is noteworthy, having trait anxiety at the level of 8 stens and more increased the risk of depression in men 38 times $[\mathrm{OR}=38 ; 95 \% \mathrm{Cl}=(5.78,249.84), \mathrm{p}<0.001]$.

\begin{tabular}{|c|c|c|c|c|c|c|c|}
\hline \multirow{2}{*}{\multicolumn{2}{|c|}{ Variables }} & \multirow{3}{*}{\begin{tabular}{|l|}
$\begin{array}{l}\text { Mean } \\
\text { difference }\end{array}$ \\
2,571 \\
\end{tabular}} & \multirow{3}{*}{$\begin{array}{l}\text { SD } \\
-0.00720 \\
\end{array}$} & \multirow{3}{*}{\begin{tabular}{|l|}
$\begin{array}{l}\text { Standard } \\
\text { error }\end{array}$ \\
0.41427 \\
\end{tabular}} & \multirow{3}{*}{\begin{tabular}{|l}
$\begin{array}{l}\text { Significance } \\
\text { (bilateral) }\end{array}$ \\
0.001 \\
\end{tabular}} & \multicolumn{2}{|c|}{ Confidence interval $95 \%$} \\
\hline & & & & & & \multirow{2}{*}{$\begin{array}{l}\text { Lower endpoint } \\
1.69514\end{array}$} & \multirow{2}{*}{$\begin{array}{l}\text { Upper endpoint } \\
3.33117\end{array}$} \\
\hline Pair 1 & Risk of depression_M - Risk of depression_F & & & & & & \\
\hline Pair 2 & Trait Anxiety_M - Trait Anxiety_F & 3,831 & 0.01748 & 0.83965 & 0.001 & 2.14935 & 5.44073 \\
\hline Pair 3 & State Anxiety_M - State Anxiety_F & 0.442 & -0.02652 & 0.89348 & 0.620 & -1.39577 & 2.10390 \\
\hline
\end{tabular}

$M$ - mother; $F$ - father 
AUC value for this model was 0.833 , which can be interpreted in terms of a relatively good efficiency of the model to predict low vs high risk of depression in men. At the same time Hosemer-Lemeshow test statistic turned out to be significant $(p<0.05)$, which may indicate that there might be other models, better fitted to the data. Therefore, the results of our model building should be treated with caution.

\section{DISCUSSION}

Depression and anxiety are known to be the most common antenatal mental health issues in both mothers and fathers, even though differences have been found in the prevalence of depression and anxiety symptoms depending on ethnic background, parity, or trimester of pregnancy [6-8]. Our results are consistent with a vast body of research, which points to higher levels of depression in expectant mothers as compared to expectant fathers [9]. However, our results are only partially in line with some studies [16], which evidenced mothers as presenting higher ratings of antenatal anxiety. In our study sample differences were found only in the case of trait anxiety. Parents did not differ in the state anxiety level. What is more, gender differences were found in the type of anxiety predictive for antenatal depression. While the state anxiety turned out to be a predictor of maternal depression, the trait anxiety significantly increased the risk of depression in fathers. It can be hypothesized that although preparing for parenthood and the upcoming delivery is stressful for both parents, the anxiety related to pregnancy and childbirth may have greater impact on vulnerability to depression in mothers than fathers. The increased level of anxiety, especially in the last trimester of pregnancy, is often described as a physiological and adaptive phenomenon, as it helps parents to reduce fantasies about the "imagined baby" [2]. Solicitude for and the concentration on the child's health and safe delivery facilitate parental preparations for meeting the real newborn. It can be presumed, however, that the very high level of state anxiety lacks its adaptive functions in mothers and puts them, and thus their expected and new-born babies, at the risk of maladaptation. Fathers, on the other hand, seem to be prone to depression more due to their personality-based predisposition to anxiety. This phenomenon needs further investigation. Quantitative measures of anxiety do not answer the question of the sources and gender-specific themes of parental concerns. Including more complex and qualitative methods to the future research could be beneficial for looking into the specificity of and gender differences in parental antenatal anxiety.

In light of our results, mood disturbances in the last trimester of pregnancy are common among primiparous Polish parents. What is especially surprising, the prevalence of the elevated level of anxiety in both parents turned out to be higher than the prevalence of the risk of depression, which is alarming. Additionally, anxiety (state or trait, depending on the parent's gender) turned out to be a significant risk factor for depression. This points to the strong need to introduce screenings not only for depression, but also for anxiety during the antenatal period. This recommendation is especially noteworthy in light of some studies which indicate that detrimental effects of prenatal depression increase when coupled with anxiety $[18,24]$. Our study also reaffirm the notion that an antenatal screening for both depression and anxiety should include fathers. The importance of taking paternal antenatal mental health seriously into account is emphasized by the study of Paulson and colleagues [14], who found stable patterns of occurrence and severity of depressive symptoms between the 3rd trimester and the 6-month postpartum in both mothers and fathers. Additionally, paternal prenatal depression was found to be predictive for worsening maternal emotional well-being [14] and for future developmental problems, including emotional-behavioral difficulties and psychiatric diagnoses in children [22].

A question arises as to the tools used for screening purposes. The Edinburgh Postnatal Depression Scale is commonly implemented in clinical practice as the only screening tool for mood disturbances with the assumption that the anxiety subscale can be distinguished in the total score. However, the specificity of symptoms as well as the pathophysiology of depression and anxiety remain distinct and thus should be examined independently, as recommended in numerous studies on perinatal mental health [13, 31, 32]. The analysis conducted by Brouwers, van Baar and Pop [33] also showed that EPDS anxiety subscale did not measure anxiety accurately. Our results add to this standpoint, as it turned out that different anxiety types are the risk factors for depression depending on parental gender.

Results of our study should be treated with caution due to numerous limitations. First of all, the sample is not representative for Polish primiparous parents as more than $80 \%$ of participants had higher education. This was unexpected as all subjects were recruited via antenatal classes, which were free of charge and open to all expectant parents who inhabited the city. It remains unclear whether well-educated parents predominated among the participants of the classes or less educated parents were not interested in participating in the study.

Secondly, gender differences in anxiety found in our study point to the problem of the gender adequacy of tools used to screen for depression in men. Paternal symptoms of perinatal depression have been far less investigated, but it is known that the manifestation of depression differs between the sexes [34]. EPDS, used in the present study, was originally created to assess maternal perinatal mood [29]. Thus, a gender-specific tool, such as The Perinatal Assessment of Paternal Affectivity (PAPA) [35] — a new self-report screening for affective symptoms in fathers during the perinatal period, 
would be more proper to assess depression in fathers. This tool, however, is yet in the process of Polish adaptation.

\section{CONCLUSIONS}

Anxiety and depression are common mood disturbances among primiparous Polish parents. High level of anxiety increases the risk of depression in both mothers and fathers. There is a strong need to screen for depression and anxiety in both parents in the prenatal period.

\section{Acknowledgements}

We gratefully thank Marta Barańska, Alicja Niedźwiecka and Kinga Dutkiewicz for coding the data and Małgorzata Subocz†, Wanda Urmańska, Beata Szol, Urszula Tataj-Puzyna, Małgorzta Lipka, and Sylwia Kuczyńska-Hosrt for their assistance with the collection of the research material.

\section{REFERENCES}

1. Ammaniti M, Tambelli R, Odorisio F. Exploring Maternal Representations During Pregnancy in Normal and At-Risk Samples: The Use of the Interview of Maternal Representations During Pregnancy. Infant Mental Health Journal. 2012; 34(1): 1-10, doi: 10.1002/imhj.21357.

2. Stern NB. Motherhood: the emotional awakening. J Pediatr Health Care. 1999; 13(3 Pt 2): S8-12, doi: 10.1016/s0891-5245(99)90049-4, indexed in Pubmed: 10531914.

3. Slade A, Cohen L. The process of parenting and the remembrance of things past. Infant Mental Health Journal. 1996; 17(3): 217-238, doi: 10.1002/(sici)1097-0355(199623)17:3<217::aid-imhj3>3.0.co;2-l.

4. Singley $D$, Edwards L. Men's perinatal mental health in the transition to fatherhood. Professional Psychology: Research and Practice. 2015;46(5): 309-316, doi: 10.1037/pro0000032.

5. Leach LS, Poyser C, Cooklin AR, et al. Prevalence and course of anxiety disorders (and symptom levels) in men across the perinatal period: A systematic review. J Affect Disord. 2016; 190: 675-686, doi: 10.1016/j. jad.2015.09.063, indexed in Pubmed: 26590515.

6. Darwin Z, Galdas P, Hinchliff S, et al. Born and Bred in Yorkshire (BaBY) team. Fathers'views and experiences of their own mental health during pregnancy and the first postnatal year: a qualitative interview study of men participating in the UK Born and Bred in Yorkshire (BaBY) cohort. BMC Pregnancy Childbirth. 2017; 17(1): 45, doi: 10.1186/s12884-0171229-4, indexed in Pubmed: 28125983.

7. Philpott LF, Savage E, FitzGerald $S$, et al. Stress in fathers in the perinatal period: A systematic review. Midwifery. 2017; 55: 113-127, doi: 10.1016/j. midw.2017.09.016, indexed in Pubmed: 28992554.

8. Woody CA, Ferrari AJ, Siskind DJ, et al. A systematic review and meta-regression of the prevalence and incidence of perinatal depression. J Affect Disord. 2017; 219: 86-92, doi: 10.1016/j.jad.2017.05.003, indexed in Pubmed: 28531848.

9. Teixeira C, Figueiredo B, Conde A, et al. Anxiety and depression during pregnancy in women and men. J Affect Disord. 2009; 119(1-3): 142-148, doi: 10.1016/j.jad.2009.03.005, indexed in Pubmed: 19346001

10. Gavin NI, Gaynes BN, Lohr KN, et al. Perinatal depression: a systematic review of prevalence and incidence. Obstet Gynecol. 2005; 106(5 Pt 1): 1071-1083, doi: 10.1097/01.AOG.0000183597.31630.db, indexed in Pubmed: 16260528.

11. Heron J, O'Connor TG, Evans J, et al. ALSPAC Study Team. The course of anxiety and depression through pregnancy and the postpartum in a community sample. J Affect Disord. 2004; 80(1): 65-73, doi: 10.1016/j. jad.2003.08.004, indexed in Pubmed: 15094259.

12. Paulson JF, Bazemore SD. Prenatal and postpartum depression in fathers and its association with maternal depression: a meta-analysis. JAMA. 2010; 303(19): 1961-1969, doi: 10.1001/jama.2010.605, indexed in Pubmed: 20483973.

13. Korja R, Nolvi S, Kataja EL, et al. The courses of maternal and paternal depressive and anxiety symptoms during the prenatal period in the FinnBrain Birth Cohort study. PLoS One. 2018; 13(12): e0207856, doi: 10.1371/journal.pone.0207856, indexed in Pubmed: 30557345.
14. Paulson JF, Bazemore SD, Goodman JH, et al. The course and interrelationship of maternal and paternal perinatal depression. Arch Womens Ment Health. 2016; 19(4): 655-663, doi: 10.1007/s00737-016-0598-4, indexed in Pubmed: 26790687.

15. Milgrom J, Gemmill AW, Bilszta JL, et al. Antenatal risk factors for postnatal depression: a large prospective study. J Affect Disord. 2008; 108(1-2): 147-157, doi: 10.1016/j.jad.2007.10.014, indexed in Pubmed: 18067974.

16. Figueiredo $B$, Conde $A$. Anxiety and depression in women and men from early pregnancy to 3-months postpartum. Arch Womens Ment Health. 2011;14(3): 247-255, doi: 10.1007/s00737-011-0217-3, indexed in Pubmed: 21479759.

17. Norhayati $\mathrm{MN}$, Hazlina $\mathrm{NH}$, Asrenee $\mathrm{AR}$, et al. Magnitude and risk factors for postpartum symptoms: a literature review. J Affect Disord. 2015; 175 : 34-52, doi: 10.1016/j.jad.2014.12.041, indexed in Pubmed: 25590764.

18. Davis E, Snidman N, Wadhwa P, et al. Prenatal Maternal Anxiety and Depression Predict Negative Behavioral Reactivity in Infancy. Infancy. 2004; 6(3): 319-331, doi: 10.1207/s15327078in0603_1.

19. Capron LE, Glover V, Pearson RM, et al. Associations of maternal and paternal antenatal mood with offspring anxiety disorder at age 18 years. J Affect Disord. 2015; 187: 20-26, doi: 10.1016/j.jad.2015.08.012, indexed in Pubmed: 26301478.

20. O'Leary N, Jairaj C, Molloy EJ, et al. Antenatal depression and the impact on infant cognitive, language and motor development at six and twelve months postpartum. Early Hum Dev. 2019; 134: 41-46, doi: 10.1016/j. earlhumdev.2019.05.021, indexed in Pubmed: 31176100.

21. Sweeney $S$, MacBeth $A$. The effects of paternal depression on child and adolescent outcomes: A systematic review. J Affect Disord. 2016; 205: 44-59, doi: 10.1016/j.jad.2016.05.073, indexed in Pubmed: 27414953.

22. Ramchandani PG, O'Connor TG, Evans J, et al. The effects of pre- and postnatal depression in fathers: a natural experiment comparing the effects of exposure to depression on offspring. J Child Psychol Psychiatry. 2008; 49(10): 1069-1078, doi: 10.1111/j.1469-7610.2008.02000.x indexed in Pubmed: 19017023.

23. Habib C. Paternal perinatal depression: An overview and suggestions towards an intervention model. Journal of Family Studies. 2014; 18(1): 4-16, doi: 10.5172/jfs.2012.18.1.4.

24. Field T. Prenatal depression effects on early development: a review. Infant Behav Dev. 2011; 34(1): 1-14, doi: 10.1016/j.infbeh.2010.09.008, indexed in Pubmed: 20970195.

25. Field T, Diego $M$, Hernandez-Reif $M$, et al. Comorbid depression and anxiety effects on pregnancy and neonatal outcome. Infant Behav Dev. 2010;33(1): 23-29, doi: 10.1016/j.infbeh.2009.10.004, indexed in Pubmed: 19945170.

26. Korhonen M, Luoma I, Salmelin R, et al. Longitudinal study of maternal depressive symptoms and child well-being. J Am Acad Child Adolesc Psychiatry. 2001; 40(12): 1367-1374, doi: 10.1097/00004583-20011200000006, indexed in Pubmed: 11765281.

27. Verbeek T, Bockting CLH, van Pampus MG, et al. Postpartum depression predicts offspring mental health problems in adolescence independently of parental lifetime psychopathology. J Affect Disord. 2012; 136(3): 948-954, doi: 10.1016/j.jad.2011.08.035, indexed in Pubmed: 21930302.

28. Deave T, Heron J, Evans J, et al. The impact of maternal depression in pregnancy on early child development. BJOG. 2008; 115(8): 1043-1051, doi: 10.1111/j.1471-0528.2008.01752.x, indexed in Pubmed: 18651886.

29. Cox JL, Holden JM, Sagovsky R. Detection of postnatal depression. Development of the 10-item Edinburgh Postnatal Depression Scale. Br J Psychiatry. 1987; 150: 782-786, doi: 10.1192/bjp.150.6.782, indexed in Pubmed: 3651732.

30. Spielberger CD, Gorsuch RL, Lushene R, et al. Manual for the State-Trait Anxiety Inventory. Consulting Psychologists Press. ; 1983.

31. Matthey S, Barnett B, Howie P, et al. Diagnosing postpartum depression in mothers and fathers: whatever happened to anxiety? J Affect Disord. 2003; 74(2): 139-147, doi: 10.1016/s0165-0327(02)00012-5, indexed in Pubmed: 12706515.

32. Field T. Prenatal anxiety effects: A review. Infant Behavior and Development. 2017; 49: 120-128, doi: 10.1016/j.infbeh.2017.08.008.

33. Brouwers E, Baar Av, Pop V. Maternal anxiety during pregnancy and subsequent infant development. Infant Behavior and Development. 2001; 24(1): 95-106, doi: 10.1016/s0163-6383(01)00062-5.

34. Madsen S, Juhl T. Paternal depression in the postnatal period assessed with traditional and male depression scales. The Journal of Men's Health \& Gender. 2007; 4(1): 26-31, doi: 10.1016/j.jmhg.2006.10.017.

35. Baldoni F, Matthey S, Agostini F, et al. Perinatal Assessment of Paternal Affectivity (PAPA): preliminary report on a new screening tool. Infant Ment. Health J. 2016; 37 (Suppl. 1): 132-133. 